\title{
Differença entre obrigações correaes e simplesmente solidarias.
}

\section{DIREITO ROMANO}

\author{
Nâo conheço na doutrina das obri- \\ gaçóes e quiçá em todo o direito civil, \\ ponto mais complicado e difficil do que \\ a theoria da solidariedade. \\ (Lacerda, n. C.) \\ 'La corr'́alité .. cette partie, la plus \\ subtile peut-être, de la legislation ro- \\ maine." (Bonnier, App. 4 L. 3 das Insts. \\ de Ort.)
}

I. - Estabelecer o criterio differencial entre as obrigações correaes e as simplesmente solidarias é uma das maiores difficuldades no estudo desta parte do Direito Civil.

Ardua questão é determinar qual o motivo por que em Direito Romano certas obrigaçōes, em que eram os diversos coobrigados responsaveis por toda a prestação, regiam-se por principios diversos dos que dominavam outras. Seriam essas differenças de natureza tal que nos autorizem a subdividir em duas classes as obrigações em que cada corréo é obrigado a pagar toda a prestação (solidum)? Ao contrario tratar-se-ia de simples differenças, presididas sim por um criterio, mas insufficientes para determinarem uma subdivisão da classe das obrigações solidarias'? Finalmente não 
seriam diversos os motivos por que os romanos abrandaram em dados casos os effeitos das obrigações, em que cada devedor terá de pagar a totalidade? Taes são as difficuldades em Direito Romano.

No direito moderno, e em face da lei de cada povo, não é menos embaraçoso saber si existe uma solidariedade perfeita e outra imperfeita, e si deve a doutrina manter tal distinç̧ão, ou de preferencia condemnal-a como enredando inutilmente materia já de si tão intrincada. (Magalhães, Obr. Sol. \3).

Não é porém das leis actuaes, mas exclusivamente da romana que vamos nos occupar.

2. - Antes de tudo attentemos na terminologia. Correi é a expressão que se emprega para exprimir os varios coobrigados in solidum, seja qual fôr a extensão de sua responsabilidade (Salivas \& Bellan, v. 2 pag. I6 I), e, o que é mais, ésta mesma expressão servia ainda para designar os credores in solidum. Dizem as Institutas duo pluresve rei, e a expressão duo rer é repetida infinitas vezes, particularmente no Digesto, titulo de duobos rers; e o vocabulo conreus no titulo de liberatione legata fr. $3 \$ 3$.

Parece que ao tempo de Cicero a expressão reus para representar o autor no processo, e naturalmente o credor, não era vulgar, mas technica. Assim diz o orador romano: '"Reos appello non eos modo qui arguuntur sed omnes quorum de re disceptatur: sic enim olim loquebantur (De Or 2, 43.)

Firmados assim os sentidos das expressões reus, duo rei, plures rei, conrei, na Florentina e na Vulgata, correi em Haloander (Sav., vi I. ${ }^{\circ}$ pag. I 57 n. ${ }^{2}$ g.), não podemos entretanto acceitar que, no caso de obrigação correal, fossem os devedores chamados conrei promittend ou duo rei promittendi, e na hypothese de obrigação simplesmente, solidaria, duo rei debendi ou 
conrei debendi, como pretende Magalhães. $\bigcirc$ fr. 9 de duobus reis por elle citado está longe de suffragar tal distinç̧ão. Trata-se no texto de obrigação nascida de estipulação, e portanto havia de ser usada a expressão rë̈ promittendi, mas dahi não se infére que a expressão debendi não tivesse applicação á hypothese. $\mathrm{O}$ que ha de verdade é que obrigação mais restricta é a originadà em regra da estipulação, e que foi considerada como a genuina correal (Serafini v. 2 pag. 48); mas é innegavel que de outros actos tambern podia nascer a correalidade pura, comquanto mais raramente (Salivas e Bellan v. 2, pag. i6o., Ortolan v. 3, pag. 8 r 7 app. $4 .^{\circ}$ ao L. 3, por Bonnier). Scot, citado por Magalhães, limita-se a dizer que se chama reus debendi o devedor, e reus stipulandi o que se obrigou por estipulação. Waldeck, ainda um dos autores referidos por Magalhães, não affirma sinão que especialmente se chamam rei stipulandi ou promitiendi os que são constituidos por estipulação, ou geralmente por convenção.

O proprio Magalhães confessa que ha textos contrarios á sua doutrina (pag. 5, n. ${ }^{\mathrm{a}} 3$ ). E' digno de nota que a obrigação a que se refere o texto em que Magalhães firma sua opinião sobre o sentido das expressões debendi e promittendi é, como abaixo veremos, correal na opinião de uns, e simplesmente solidaria na de outros. (Salivas \& Bellan v. 2 pags. i6o e I6I).

Savigny adoptou para exprimir a simples solidariedade a locução correalidade impropria (unächte correalität). Parece-nos que as expressões geralmente adoptadas-correalidade e simples solidariedade-bastam para as explicações doutrinarias, e exprimem sufficientemente a differença entre as duas especies de obrigações, si é que existe tal differença com caracteristicos taes que autorizem a creação de uma subdivisão. 
Em falta de outras consagradas pelas fontes, adoptaremos éstas designações, mais geralmente acceitas que as de Savigny, não obstante reconhecermos que as deste grande romanista exprimem com mais vivacidade a incontestavel differença que algumas obrigações, em que os devedores são obrigados pela totalidade, têm da genuina, primitiva e propriamente dita obrigação correal (1). Não nos esqueçamos de que nas fontes obrigação in solidum quer por vezes significar a que vae alem das forças da herança, ou que excede ao valor da noxa (Sav. Obr. v. I. pag. I 58 e I 59).

Lacerda (Obr. $\$ 7$ e n. ${ }^{a}$ C. pags. 32 i. f. e 447) Windscheid ( $\$ 293$ e 298), Magalhães (Obr. Sol. pag. 6), e muitos outros adoptam as expressões a que nestes apontamentos damos preferencia. Ha outras designações, convindo mencionar identidade e solidariedade de Ribbentrop, que bem caracterisam sua doutrina (Sav. Obr., trad. de Gerardin \& Jozon, v. I, pag. I 57).

3. - A distincção entre obrigações correaes e solidarias foi ideada no começo do seculo passado.

Lacerda a colloca em data posterior a r824 (n. ${ }^{a}$ C.); quando. diz elle, Keller e Ribbentrop tiveram diante de si as fontes juridicas antejustinianeas. Bonnier (app. ao L. 3 de Ort), assegura que, quando Ortolan annotava as Institutas (1827), não existia ainda tal doutrina.

Ainda em I 829 , diz. Windsheid, podia-se affirmar com Guyet não ser facil achar-se em nenhum ponto essencial de direito romano litteratura mais escassa que a referente ás obrigações solidarias ( $\$ 292$ n. $\left.^{a}{ }^{*}\right)$. Hoje as obras sobre essa materia são infinitas, e até colossal o numero de trabalhos ainda acerca da formula

( $\left.{ }^{1}\right)$ A expressão alleman ächte corresponde ás vernaculas genuino, proprio, lidimo, legitimo, puro, natural, verdadeiro, etc. 
"unidade de obrigação e pluralidade de relações subjectivas" para designar a essencia da obrigação correal, como se pode ver na nota $*$ ao $\ 293$ do Direito das Pandectas de Windscheid. Com razão disse Lacerda que o debate neste assumpto parece interminavel (pag. 446.)

O mais digno de menção porém é que todas as doutrinas cuidadosamente architectadas vão perdendo o credito, e ha tendencia a abandonal-as como insufficientes para explicar as differenças accidentaes, que se notam nas leis romanas sobre os principios que regem algumas das obrigações, em que cada um dos corresponsaveis deve fazer a prestação total (in solidum).

Tractando da formula de Keller e Ribbentrop - "unidade de obrigação e pluralidade de relações subjectivas" - para caracterisar a obrigação correal, pedra angular no assumpto, e abalada entre $\mathrm{I} 85^{\circ} \mathrm{e}$ I 860, diz Windsheid que um artigo de Unger reaccendeu a controversia, e hoje é pouco animador o estado da theoria supra referida, e de que mais de espaço vamos em seguida nos occupar.

4. - Antes de entrarmos no rapido estudo do que em geral se tem dicto sobre a differença entre obrigações correaes e simplesmente solidarias, diremos em duas palavras o que pensamos a este respeito.

Sem preocupações metaphysicas, tinham os romanos a obrigação correal, que satisfazia á necessidade da segurança do cumprimento do contracto, de que tanto cogitavam dum curamus ut diligentius nobis cautum sit. Neste afan organisaram muitos institutos (Gaio 3, I I 7 e sgs.) Ora, era natural que assim como applicaram os romanos a fiança e todas as sortes de garantias, em que eram fecundos (Labbé app. 5 L. 3 Ort.), a outras formas de contractos que não a estipulação 
(Inst. de fidej. $\ I^{\circ}$ ); e assim como a estipulação foi aproveitada até para as cauções judiciaes (Inst. de divis. stip. $\$ I , de verb. Obl. fr. 5 . Inst. de sat. $\$ 4$ ), assim tambem extendessem os principios da correalidade a outros casos que não o da primitiva estipulação. Mas; assim como, á medida que estendiam a applicação das dividas accessorias a casos que não os primitivos, iam lhes modificando os principios dominantes. (Labbé App. 5 L. 3, Ort. Gaio C. 3 n. $^{\text {os }}$ I 20 e I 2 I ), assim tambem modificaram os rijos principios da correalidade primitiva á proporção que a extenderam a outros casos. E' certo que nos contractos accessorios as modificações foram ás vezes tão profundas (Ortolan. n. I 565) que julgaram os romanos dever lhes dar outros nomes (Gaio C. 3, ns. i I 5 e I I 8), e caracterizal-os como institutos sui generis. A tanto não chegaram quando extenderam a applicação da correalidade.

Querer lobrigar um criterio unico nas ampliações desta ou de qualquer outra instituição, é emprestar aos romanos preoccupações theoricas que nunca tiveram, não obstante a reputaçã̃o de methodo geometrico que lhes attribuiram os modernos (Labbé a Cuq p. XVII). Abaixo, mais minuciosamente exporemos nossa opinião, que, em summa, é terem sido feitas rebus dictantibus et necessitate exigente as modificações nas regras que regiam nos primordios do Direito Romano as obrigações correaes.

Nenhum criterio philosophico e anticipado determinou as pequenas alterações, que se notam em algumas relações de correalidade, a que denominam, em geral, como dissemos, os modernos simples solidariedade.

5.-Agora vejamos o que dizem os jurisconsultos modernos sobre o criterio que levou os romanos a 
subdividirem a classe das øbrigações em que cada coobrigado terá de pagar a totalidade. A éstas obrigações podemos chamar solidarias em sentido lato, pois comprehendem as correaes e as simplesmente solidarias. Acompanhando a Raul de la Grasserie, dá Lacerda como criterio differencial entre as duas classes de obrigações (correaes e simplesmente solidarias) a unidade ou pluralidade do laço obrigatorio. A redacção da nota por Lacerda ( $n .{ }^{a}$ C.) e do trecho de R. de la Grasserie é tão infeliz que, á primeira leitura, parece ser ésta a unica doutrina, que se tem ideado, para explicar a differença observada no modo de legislarem os romanos para as diversas especies de obrigações solidarias em sentido lato.

Abaixo veremos que foram propostos outros criterios, comquanto seja a doutrina que nos occupa neste momento a que maior numero de adeptos conta. (Windsheid n. ${ }^{\mathrm{a}}$ I ao $\$ 293$ ).

Ha um texto que parece bem caracterizar ésta doutrina, e é o fr. $3 \$$ I de Ulpiano (de duobus reis), quando diz: "Cum una sit abligatio una ct summa est." Mas Windsheid confessa que póde se considerar como reconhecido- "che la maniera d'exprimersi delle fonti non sia decisiva》 (cit. n. I ao $\$ 293$ ). Neste ponto, como em quasi todos os outros, a Windsheid acompanha Lacerda, e referem ambos algumas fontes em que, a este proposito, se falla de plures obligationes. Tentam desfazer a contradição dos textos, dizendo que plures obligationes ha sob o aspecto das modalidades por que se acham vinculados os corréos, e una obligatio existe quanto ao vinculo obrigatorio propriamente. Esta e outras agudas e engenhosas explicações referidas por Windsheid como apresentadas por Kuntze, Rückert; Helmolt, Fritz, etc. seriam optimas si fossem os jurisconsultos romanos tão sagazes e atilados em 
materia philosophica quanto o eram os sophistas gregos.

De I850 a i 860 a theoria da - "unidade da obrigação com pluralidade de relações subjectivas" foi vigorosamente criticada, e appareceram então as doutrinas harmonicas, que são em numero elevado, e se encontram em parte comprehendidas na nota que nos vae servindo de apoio para éstas breves observações (n. I ao $\ 293$ do Diritto delle Pand. de Windsheid.)

6.-Contra o systema explicativo da differença entre as duas especies de obrigações, proposto por Keller e Ribbentrop, seguido por Lacerda e Windsheid, e modificado por outros jurisconsultos, temos o de Serafini, que se diz apoiado em Landucci. (1).

Nega Serafini a unidade do vinculo, e diz, referindo-se ás obrigações -solidarias lato sensu: $\mathrm{O}$ caracteristico das obrigações in solidum acha-se no objecto, que é egual: ora, ésta egualdade póde se conceber de dois modos, a saber identidade ou simples egualdade. Noutras palavras, as varias obrigaf̧öes que entram no vinculo solidario pódem ter um objecto unico, só, commum a todos, ou um objecto separado, independente para cada um, mas egual.» Define ainda a correalidade dizendo que é "um conjuncto de obrigasóes, $\epsilon \mathrm{m}$ que varios individuos teem o dever de prestar identico objecto.; Definindo a simples solidariedade, diz que é tambem "um conjuncto de obrigafões, tendo cada uma um objecto egual ao das outrass. Serafini não cita leis em apoio de sua opinião, mas reporta-se, como dissemos, a Landucci.

(1) Não encontramos a obra de Landucci Le Obligazioni in Solido, Padova, 1880. Para a composição destas breves notas sobre o assumpto, não tivemos tempo de a encommendar a livreiros da Italia. 
Confessamos que nos causou extranheza a doutrina do illustre mestre. Que dissesse elle ser indifferente que indicassem as fontes um só laço obrigatorio, ou multíplicidade de laços nas obrigações solidarias em sentido lato, que dahi nenhum criterio se poderia tirar para classifical-as em correaes e simplesmente solidarias, nada nos pareceria mais acertado. O que nos admira é que affirme que em todos os casos ha sempre pluralidade de obrigações. Acreditamos que os romanos formavam clara idea do vinculo unico, sem embargo de serem pouco dados ás investigações philosophicas. Bastam dois textos para provar nosso asserto. Será o primeiro o já citado fr: $3 \S I$ de duobus reis, e o segundo o fr. 9 de pactis, que diz «unius loco numerabuntur quia unum debitum est", e mais abaixo unus tutor plurum pupillorum nomine unum debitum pretendentium, si convenerit.»

Debitum aqui é o laço o juris vinculum (I. de obl. pr.), e não a somma devida. Traduzir de outro modo seria torturar o texto, e alterar o sentido da expressão latina consagrada.

Ahi temos face a face duas doutrinas oppostas: a de Keller, que acceita a unidade ou pluralidade no vinculo obrigatorio como criterio para distinguir obrigações correaes das simplesmente solidarias; e a de Serafini, que assegura nunca haver unidade do vinculo, mas sim do objecto da obrigação. Já nos referimos ás opiniões harmonicas numeradas por Windsheid, e que procuram explicar os textos, que ora fallam de uma obrigação, ora de muitas.

Agora nos é pois licito passar á doutrina da representafão, que parece uma variante dà de Keller

7 -Notando Brinz, diz Windsheid, que a unidade do vinculo obrigatorio não bastava para explicar a a extinç̧ão da obrigação correal pela litiscontestação, 
vișto dar-se a falta do requisito ecedem persona, imaginou haver no caso a representacão entre os coobrigados, e dest'arte explicava como não se fazia a consumpção processual em caso de obrigações simplesmente solidarias. Nestas, entende Brinz, não ha a representação (Windsheid n. 3 ao $\ 298$ ). Tal é em traços geraes a doutrina da representação. A nosso ver é a mesma doutrina da sociedade, e que parece acceita por Magalhães em face dos textos romanos (Obr. Sol. pag. 4 n. I.), mas repellida no direito moderno (pags. 50 a 52 , ns. 60 e 6I.) Só da primeira parte temos de nos occupar. Nascendo em geral a obrigação correal da estipulação, e tendo sido estendida a outros casos pela lei, claro é que geralmente havia no primeiro caso uma especie de sociedade formada pelos compromettentes, e no segundo não. Mas era uma simples coincidencia. Cita Magalhães o fr. 9 de duobus reis const., mas esquece-se de que ha quem sustente que não se trata ahi de obrigação correal, mas de obrigação simplesmente solidaria (Salivas \& Bellan, pag. I6I), pois a obrigação do depositario mencionado no fr. 9 não se consome pela litiscontestação (dep. fr. I $\$ 43$ ). O fr. ro eod., que é continuação do antecedente, não o esclarece, mas limita-se a estabelecer que no caso de não haver sociedade entre os coobrigados, não é licito compensar com o que o credor deve a um delles: regra muito singular e especial é ésta, que não podemós generalizar, e tornar fundamento de uma theoria.

O fr. 62 ad Legem Falcidiam, longe de servir para suffragar a distincção das obrigações solidarias lato sensu em correaes e simplesmente solidarias por meio do criterio da sociedade, parece acceitar este criterio para distinguir a responsabilidade in solidum, e a por partes viris, parcial ou de conjunç̧ão ordinaria, empregando a expressão preferida por Magalhães para 
designar o casø de nãø ser cada devedor rosponsavel pela totalidade, mas por uma parte (Obrg. Sol. pag. 2). Eis o teor do texto: "Sì houver dous cocredores ou dous codevedores, no caso de serem socios, deve a obrigação ser entre elles dividida, como si cada um tivesse dado ou promettido uma parte do dinheiro: mas si entre elles não havia sociedade, é duvidoso dos bens de qual dos obrigados se deva tirar o devido."

Já esperamos pela objecção: "o texto tracta de correos obrigados solidariamente, pois diz:-si duo rei promitlendi fuerint-, e duo rei são sempre solidariamente responsaveis.» Mas respondemos: o texto é positivo quando diz atque si singuli partem pecunice promisissent. Magalhães deixa de citar um texto onde se vê que no caso de ser legada a um de "duo rei promittendi» a divida, tal legado não aproveita ao outro, quer sejam socios, quer o não sejam; mas que no caso de serem socios, deve o beneficiado ser desonerado por acceptilação, e no caso contrario por pacto. Esta é, diz Ulpiano, a opinião de Juliano.

A este fragmento segue-se outro aindā de Ulpiano (fr. 5) nos seguintes termos: " $\mathrm{Si}$ ao fiador fôr legada a quitação de uma divida, sem duvida (como tambem escreveo Juliano) deverá o fiador ser desonerado por pacto: mas aqui julgo que algumas vezes (interdum) deverá ser desonerado por acceptilação, quer fosse na realidade devedor, quer socio do réo no devido (in rem socius reus)".

Destes dous textos se infere que a circumstancia da sociedade, comquanto tornasse mais forte o laço obrigatorio fazendo até, na opinião de Ulpiano, necessaria a acceptilação para a exoneração do devedor, entretanto não era tão caracteristica que pudesse servir de criterio para assignalar uma classe especial de obrigações, sendo digno de toda a attençãó 
que Juliano a julgava tão pouco importante, que não entendia por ella tornar-se precisa a acceptilação, modo mais energico do que o pacto (de fid. et mand. fr. $7 I \$ I^{\circ} .^{\circ}$ de pactis fis. 23 e 25) de atacar o vinculo obrigatorio por ser equiparado ao pagamento (I. quib. $\bmod$ \& $I^{\circ} .^{\circ}$.

Não nos parece em summa, que a sociedade ou representação seja criterio sufficiente para distinguir as obrigações correaes das simplesmente solidarias.

8. - Sustenta Demangeat que no direito antigo a acção movida contra um dos co-devedores obrigados pela totalidade (in solidum) exonerava os demais, com certeza ao menos quando nascia a obrigação de uma estipulação ou de uma expensilatio. A' primeira vista poderia parecer que outro tanto não se dava no caso de legado, por causa do fr. $8 \rrbracket 3^{\mathrm{I}}$ de legatis I. $^{\circ}$, mas é fóra de duvida que as expressões et solutum foram postas pelos compiladores do Digesto para que não ficasse o texto em opposição ao disposto na const. 28 de fid. Cod. A interpolação é denunciada até pelo final do fragmento em que transparece, como bem observa Demangeat, o principio antigo. Sem nos determos noutras considerações acerca desse conhecidissimo texto, referiremos que Demangeat cita o fr. $I .{ }^{0} \& 43$ dep. e outros, em que apparecem obrigações solidarias, que não se extinguem pela propositura da acção contra úm dos devedores: "Nec liberabitur alter, si cum altero agatur; non enim electione, sed solutione liberantur". Nota então "quill s'agit toujours de débiteurs tenus d'une action de bonne for ou d'une action in factum. I'en conclus que l'ancien principe en vertu duquel tous les débiteurs étaient li-berés par la litis-contestatio formée avec l'un d'eux s'appliquait seulement au cas où le créancier avait une condictio, c'est-à-dire quand il $y$ avait eu stipulation 
ou expensilatio, mutuum ou legs: en dehors de ces hypothèses il peut $y$ avoir des débiteurs tenus in solidum, il ny a pas des véritables correi promïtendi; et l'intérêt de la distinction consiste notamment en ce que la litiscontestation n'a l'effet extinctif du paiement que là où il s'agit de corréalité proprement dite». (V 2 pags. 267 e 268).

Contra a doutrina de Demangeat oppõe Bonnier um conhecidissimo texto de Papiniano (de duobus reis fr. 9), onde apparece o deposito como gerando obrigação correal, não obstante ser a obrigação do depositario do numero das que não se extinguem pela litiscontestação, como se vê nọ fr. I. $.^{\circ}, 3$ dep., citado por Demangeat. Funda-se Bonnier na locução funt duo rei permittendi empregada por Papiniano para provar que o caso é de correalidade propriamente dicta.

Eloquente é de facto ainda contra Demangeat a c. I Cod. de cond. furtiva tambem citada por Bonnier em que, não obstante tratar-se de uma condictio, não se dá a consumpção da obrigação sinão pelo pagamento.

Reconhecer Demangeat que fôra dictada a lei odio furum é dar força á opinião que aventurámos no principio destas notas, a saber-que neste assumpto andaram os romanos ás apalpadelas.

Antes de passarmos adiante, cumpre-nos, como entre parenthesis, notar que além de não ser provavel que houvesse um criterio unico para modificar os effeitos da correalidade, transparecem nas fontes, atravez das multiplas interpolações, vestigios de desaccordo entre os jurisconsultos romanos (Ferrini n. ${ }^{\mathrm{a}} 3 \cdot^{\mathrm{a}}$ n. 434, Man. de delle Pand).

9.- Vejamos qual a importancia da consumpção do laço obrigatorio pela litiscontestação para servir de 
indicio revelador da correalidade ou solidariedade simples da obrigação, quando examinamos as fontes.

Préliminarmente é de saber que a litiscontestação extinguia a obrigação em que se fundára o juizo legitimo, e creava por quasi contracto uma outra. (Gaio 3 n. I 80).

Aqui observaremos que ésta differença confirma a opinião que vimos defendendo, ist $₫$ é, "que o antigo rigor, manifestado pelo effeito extinctivo do laço obrigatorio no juizo legitimo ou primitivo, foi abrandado nas novas acções, representando um progresso no direito, que sacrificava os principios primitivos á conveniencia de ser o credor pago, ordem de idéas que se manteve até a const. 28 de fid. Cod., applicavel aos fiador.esi. Is.to, que se dava relativamente aos effeitos da litiscontestação, era o reflexo do que se passava quanto ás obrigações solidarias lato sensu, cujos effeitos eram modificados á medida das conveniencias do progresso juridico.

A obrigação correal primitiva, repetiremos, que se formava pela estipulação (Sav. Obl. v. i..$^{\circ}$ pag. I 72), e que apparecia em mais algumas hypotheses, era rigida, e ligava todos os co-obrigados, como si fossem uma unica pessôa; mas, estendida e applicada a outros casos, particularmente ao de resarcimento de damno (Windsheid $\ 298$ i. f.), foi regulada por outros principios em algumas de suas consequencias. Querer porém estabelecer principios fixos para formar duas sub-classes de obrigações solidarias, e procurar para esse fim um criterio unico em meio ás variedades infinitas das hypotheses, entre textos interpolados, e quiçá ainda luctando com a diversidade de opiniões dos jurisconsultos romanos, eis o que nos parece buscar o impossivel. 
Tornando porem ao ponto do assumpto de quie ora tratamos, diremos que o principal defeito do criterio da litịscontestação é não ser de resultado pratico. Com effeito, raramente dizem os textos si a obrigação é ou não consumida pela litiscontestação, como succede no fr. $5 I \$ 4 .^{\circ}$ de evict. e no fr. $I .^{\circ} \S 43$ dep., que servio de pedra de toque a Salivas \& Bellan (v. 2 pg. I6r), para affirmarem que a obrigação a que se refere o fr. 9 de duobos é solidaria simples e não correal, como parecia a alguns, que se deixavam guiar pela locução funt duo rei. Seja dicto de. passagem que é bem possivel fosse interpolado o fr. $I .^{\circ} \S 43$ dep., e que por descuido escapasse á revisão de Triboniano o fr. $g$ de duobus.

Ainda para mostrar a insufficiencia do criterio da litiscontestação, figuraremos o caso da sentença condemnatoria (onde a litiscontestação era impossivel), que expressamente estabelece a solidariedade excepcional de varios vencidos (Cod. c. I si plures), e que é considerado como de correalidade por Salivas \& Bellan (v. 2 pg. I60) e por Savigny (v. I. ${ }^{\circ}$ pg. I 78 ).

10-Exponhamos o que ensina Savigny sobre-a materia que nos occupa.

Como de costume, é seu estudo profundo, acompanhado de minuciosa analyse dos textos e das especies, ficando o assumpto exposto com muita clareza.

Diz que na solidariedade impropria, que nós temos denominado simples, notam-se não só certas consequencias isoladas, differentes das produzidas pela correalidade perfeita, mas tambem differença essencial (pag. 2 I9). Examina caso por caso todas as especies de solidariedade impropria.

Em primeiro logar aponta a obrigação nascida do delicto e ŕlativa á indemnisaf̧ão. Lembra que 
os delictos geram as acções bilateraes, que teem por objecto a pena; e as unilateraes, que se destinam a alcançar a indemnisaf̧ão. Pela pena são obrigados todos os codelinquentes, executada por um, sel-o-á de novo pelo outro. Julga Savigny que deve insistir bem sobre este ponto, e diz: "Quand deux personnes tuent en commun le cheval d'autrui, qui avait une valeur de cent dans la dernière année, chacun paie cent, et le propriétaire obtient ainsi deux cents"

Regra diversa rege a obrigação de indemnisar. Paga que seja a totalidade por um dos co-obrigados, ficam os outros desonerados. E' desta que temos de nos occupar, e Savigny insiste em que: "En ce qui touche les effets principaux, les actions pénales unilatérales concordent avec le raport de corréalités (pag 224). Mas differe daquella em que só se extingue pelos actos que equivalem a pagamento, quando praticados por um só dos devedores, mas não pela acceptilação, pelo pacto, pela transaç̧ão, nem pela litiscontestação, nem pelo juramento, nem pela sentença absolutoria (pg. 224).

Em segundo logar occupa-se Savigny da responsabilidade dos codepositarios, e menciona que a obrigação não se extingue pelo facto de se mover a acção contra um delles (dep. fr. I $\S 43$ ), o que succederia si fosse ella propriamente correal. E' assumpto de que por mais de uma vez nos occupámos nestas notas, e portanto deixaremos de repetir o já dicto. $\mathrm{O}$ que ha de mais interessante é que Savigny julga dar-se na hypothese uma respnosabilidade filha de um verdadeiro delicto (pg. 227). A par do deposito colloca o commodato, e equipára os commodatarios aos depositarios no caso de furto da cousa por um terceiro.

Em terceiro logar enumera a obrigação dos cotutores, que equipára aos casos de deposito, locação, commodato e de acções penaes para indemnisação, 


\section{$-23-$}

e diz que "ainda nesta hypothese o pagamento feito por um dos devedores exonera aos demais; mas nenhum dos outros modos de extinç̧ão das obrigações exerce influencia geral e decisiva, a menos de se poder considerar como equivalente na realidade ao pagamento.

Em quarto logar, finalmente, tracta das obrigações que geram as acções adjectitioe qualitatis, e depois de estabelecer a hypothese em que o emprezario da operação não é verdadeiramente devedor, mas obrigado subsidiariamente (de exerc fr. $5 \$ I^{\circ}{ }^{\circ}$ ) pelo preposto, diz que uma novação com aquelle, salvo corresponder a um pagamento, não desoneraria a este.

Sem querermos nos deter por mais tempo na exposição da doutrina de Savigny, resumiremos seu pensamento em duas proposições:- I ${ }^{a}$ nalgumas obrigações verdadeiramente delictuaes, estatuio a lei a solidariedade, mas ésta não se extingue por todos os modos que actuam na obrigação correal, e sim somente pelo pagamento, ou por actos equivalentes a pagamento; - $2 .^{\mathrm{a}}$ nalguns casos ha solidariedade, mas com responsabilidade subsidiaria de alguns dos coobrigados, e então actos em favor destes que não corresponderem a pagamento não desoneram aos principaes responsaveis, e isto se dá nas actiones adjectitioe qualitatis. Entende pois na verdade Savigny que não ha um criterio unico para serem creadas obrigações simplesmente solidarias, mas que a lei as estabeleceu casuisticamente. Certamente com essas premissas poderia o romanista chegar á cònclusão de que a simples solidariedade em certas obrigações não passa de modificação dos effeitos das obrigações correaes propriamente dictas, mas preferio collocar-se no numero dos jurisconsultos que subdividem a classe das obrigações solidarias lato sensu. 
11.- Van Wetter, Maynz, Ortolan, Namur (Van Wetter $\$ 336 \mathrm{e} \mathrm{n}^{\mathrm{a}}{ }^{\mathrm{r}}{ }^{\mathrm{a}}$ ) julgam inadmissivel a subdi visão das obrigações em correaes e simplesmente solidarias. Acreditamos que nenhum outro criterio guiou os jurisconsultos romanos na modificação dos effeitos da solidariedade a não ser o das necessidades de momento.

Certamente, como observa Labbé (App. 4 L 3 Art. pg. 824), a modificação na maneira de executar, as sentenças, mitigada a sorte dos devedores condemnados, actuou decisivamente para que as obrigações solidarias mais recentes só fossem extinctas pelo pagamento eftectivo ou por acto equivalente; e não pela litis contestação (solutione non electione.)

12.-Tempo é pois de acabar com esse espantalho, que aterrorisa aos que estudam a materia das obrigações-differensa entre as obrigasōes correaes e simplesmente solidarias.

Fazemos votos para que de todo passe de moda ésta supposta differença, que alguns mestres, por excesso de subtileza, julgaram encontrar nas leis romanas, e se escreva em relação a essa doutrina: $V a$ cuum est et superfluum verbum, per quod animi juvenum, qui ad primam legum veniunt audientiam, perterviti ex primis eorum cunabuilis inutiles leges antiqua dispositiones accipiunt.» (Cod de nudo jure quiritium c. un.)

Si tiveram os jurisconsultos romanos, o que é pouco provavel, algum criterio a provi para distinguir éstas duas especies de obrigações, não puderam ainda o descobrir os modernos. Poderão continuar em suas investigações sobre o assumpto alguns sabios, mas cumpre retirar dos estudos classicos uma tão enreda- 
da materia, onde fervem as duvidas, e particularmente banir das leis modernas tão descabida distinç̧ão, de nenhuma vantagem pratica, e propria só para tirar á doutrina a simplicidade desejavel.

\section{Dr. Goão Arruda}

